$\left.{ }^{*}\right)$ Mestrando em Direito das Relações Econômicas Internacionais pela PUC/SP. Especialista em Direito Internacional pela PUC/SP. Especialista em Gestão de Negócios Internacionais pelo SENAC/SP. Bacharel em Direito pela FMU com Módulo na University of Lódz'Faculty of Economics and Sociology "Social-Economic Integration In Europe in the Period of Global Crisis". Bacharel em Relações Internacionais pela UNILUS. Advogado com foco em comércio exterior. Professor do Curso de Especialização em Direito Internacional do Cogeae/PUC-SP. Membro Efetivo da "Comissão de Direito Aduaneiro" da OAB, nomeado em 2015 pela Portaria № $180 / 15 / P R$.

\title{
A REALIDADE GLOBAL DE UNIFORMIZAÇÃO DAS PRÁTICAS DE COMÉRCIO
}

Ígor Santos Katz (*)

1. Alguns aspectos da necessidade de padronização do comércio internacional

Há forte conviç̧ão de que as regras do Direito Aduaneiro não contrariam os institutos legais brasileiros, sobretudo, a Constituição Federal de 1988, porém, há muito trabalho e grande desafio para todos estudiosos do Comércio Internacional em uniformizar as regras e boas práticas aproximando-se da tão famosa Lex Mercatoria, que mais parece um Instituto atual do que retrógrado, uma vez que, o Estado tende a se distanciar das regras de Comércio Internacional a fim de facilitar as trocas entre Estados e Continentes. Não obstante, aos que pensam que o Estado pode temer a perda do controle, parece que a cada dia deixa de ser uma escolha e passa a ser uma necessidade para que o Estado se torne mais competitivo internacionalmente.

A exemplo, cito a revisão aduaneira, que traz insegurança jurídica, ao ter que se decidir qual será a classificação fiscal de uma mercadoria. As aduanas e controles aduaneiros de todos os países tem procedimentos ora assertivos, ora duvidosos, acerca do mesmo produto. Outros grandes desafios a Aduana

http://revistasapereaude.org/index.php/edicoes/ano-5-volume-3-outubro-2016

D.O.I: 10.20523/sapereaude-ano5-vol-3-pg-121-138 
mundial são: o livre comércio versus protecionismo; trafico de drogas; lavagem de dinheiro; meio ambiente; propriedade intelectual; tráfico de pessoas. Considerando que a segurança jurídica é garantia do passado, mais a certeza no presente e a possibilidade de planejamento no futuro, a de se buscar a determinabilidade das normas e das decisões, pois é essencial para se ter decisões coerente, com fundamentação suficiente e controláveis.

Nos mais variados fóruns de comércio internacional constarão na pauta as discussões em torno da complexidade da regulamentação nacional, os avanços que já foram feitos neste século, perante a expectativa e desafios das principais organizações do comércio internacional, bem como, da relação jurídica desencadeada por um processo de revisão aduaneira devido à classificação fiscal de sua mercadoria ou ações protecionistas que trazem insegurança jurídica para pequeno importador brasileiro, que ao importar insumos da Alemanha, produzirá peças e equipamentos no Brasil, e posteriormente, através de um regime aduaneiro denominado como Drawback exportará para a China equipamento de maior valor agregado, graças ao erário que de abriu mão do recolhimento dos impostos para que este exportador pudesse ter maior competitividade global. Até ai tudo parece normal, salvo pelo fato de que este empresário terá que apresentar uma série de documentos perante Ministérios, Secretarias e Autoridades Portuárias que nem sempre estão em perfeita harmonia.

Nada obstante, terá o empresário brasileiro que obter um seguro de crédito a exportação, terá também que ser um operador econômico autorizado, terá ainda que negociar um contrato internacional de compra e venda de mercadoria, em inglês com o produtor alemão dos insumos necessários à 
produção, negociar seu produto com possíveis compradores da Ásia, redigir uma minuta de contrato internacional em algum idioma estrangeiro, embarcar o produto em um navio de bandeira filipina, contratar o seguro de frete com uma seguradora inglesa, acertar o pagamento do preço em moeda conversível no exterior e o meio de pagamento por uma carta de crédito emitida por um banco chinês, que será confirmada por um banco holandês de primeira linha. Isto sem contar, negociações nacionais e internacionais com intervenientes da cadeia de supply chain, como por exemplo: o depositário de mercadoria, os transportadores, os agentes, os armadores, corretoras de câmbio, despachantes, etc.

É por isso que, diferentes instituições internacionais, como a Organização Mundial do Comércio (OMC), Organização Mundial das Aduanas (OMA), a Organização para a Cooperação e Desenvolvimento Econômico (OCDE), o Instituto de Roma (UNIDROIT) e a Comissão das Nações Unidas de Direito do Comércio Internacional (UNCITRAL), vêm-se ocupando de um dos maiores desafios do século XXI, que é a importante tarefa de uniformizar e regulamentar aspectos do comércio internacional, dentre os quais a uniformização merece destaque, uma vez que os contratos internacionais de compra e venda de mercadorias representam a base do comércio mundial.

2. O Brasil e a uniformização das regras de comércio internacional.

Tendo em vista que as Relações Econômicas Internacionais viabilizaram o descobrimento de novos mundos, e o crescimento das relações comerciais entre 
países e continentes, é importante analisar a confiança jurídica que o comércio enseja e os aspectos legais do Comércio Internacional e do Direito Aduaneiro. Neste cenário somos protagonistas, pois recentemente o Brasil chegou a ser a $7^{\text {a }}$ maior economia mundial (PIB), e está entre os 20 maiores exportadores do mundo. Como se vê abaixo, de 2000 a 2013 o desempenho do comércio exterior brasileiro foi bem superior ao da média mundial.

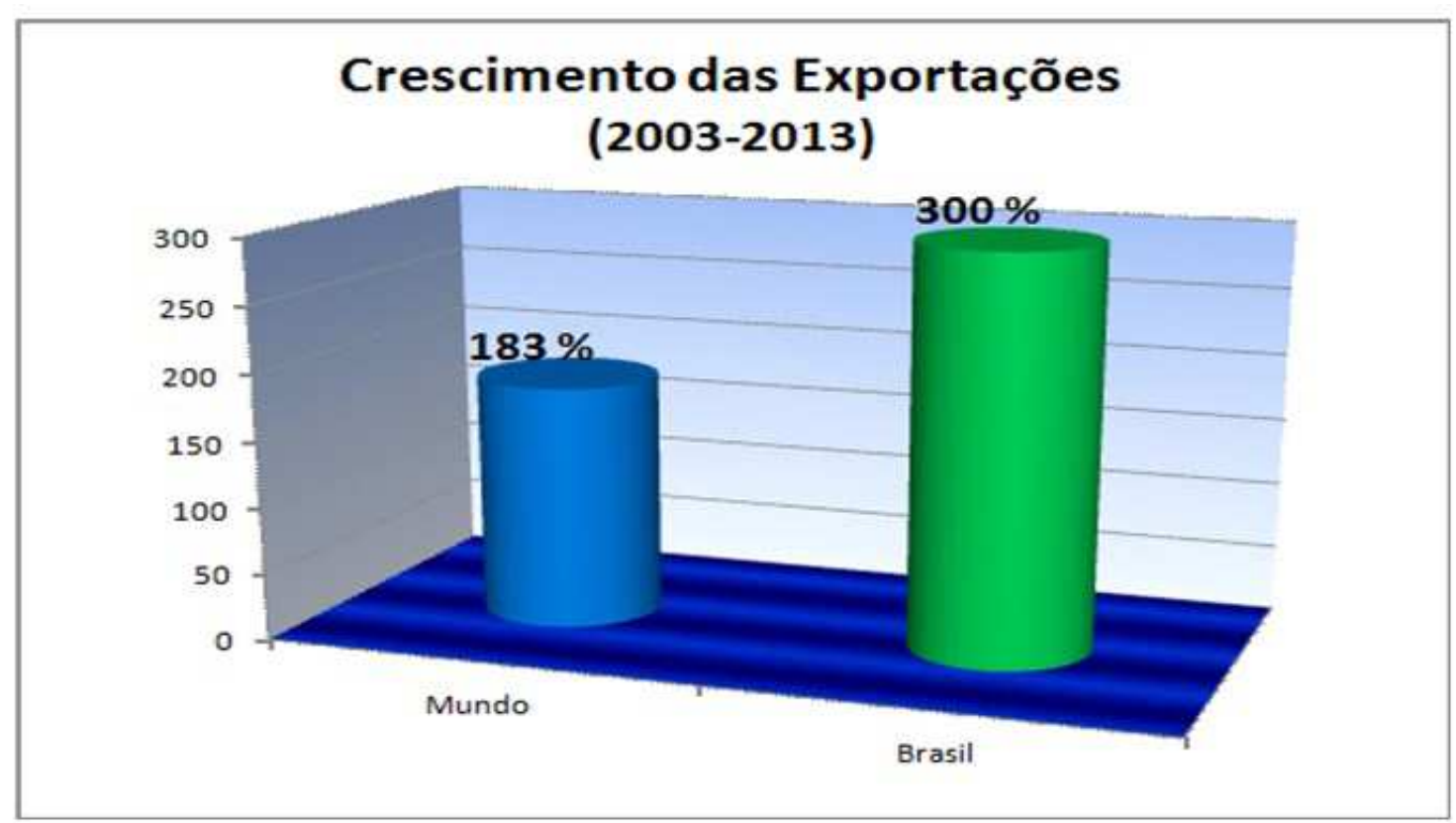

Ao analisar o cenário internacional, torna-se fácil constatar a grande complexidade e diversidade de leis, usos e costumes que regem os negócios internacionais atualmente. O resultado é que as empresas sem experiência internacional e, em particular, as pequenas e médias empresas acabam inibidas diante do desafio do comércio exterior. Por conseguinte, torna-se fundamental à organização de um sistema jurídico universal, que contenha um conjunto mínimo de regras materiais, que possa assegurar um justo equilíbrio nos contratos de compra e venda internacionais. 
O fenômeno da globalização fortaleceu o processo de integração regional, que intensificou definitivamente as relações comercias entre os países, de forma irreversível. Com isto, as normas jurídicas de outros países estão cada vez mais em evidência, tornando a tão sonhada unificação das normas jurídicas comerciais entre os países não mais uma utopia e sim uma necessidade para a evolução do comércio internacional.

Os aspectos jurídicos das relações comerciais envolvem uma gama de possibilidades e acontecimentos que apesar de consubstanciar-se numa modalidade muito antiga que é o comércio, quer seja entre nacionais, quer seja entre estrangeiros, ainda hoje oferece insegurança jurídica, sobretudo, pelo fato de envolverem partes de nacionalidades diferentes e, consequentemente, leis e estatutos diversos.

Ao se analisar as semelhanças entre os principais estatutos de comércio internacional, lembramos a atual Lex mercatoria, enaltecendo as leis que protegem esta modalidade de comércio, e as formalidades existentes entre 0 exportador e importador, que é o elo principal entre a oferta e a demanda.

"O objetivo central da OMC, assim como o do GATT, não é promover o "livre comércio", segundo a percepção frequentemente difundida na imprensa e até mesmo nos meios políticos e acadêmicos." A OMC é uma instituição internacional que tem como objetivo a regulação do sistema mundial do comércio por meio de um conjunto de princípios, acordos, regras, normas, práticas e procedimentos. Conforme os próprios documentos oficiais da OMC, "não é uma instituição livre cambista", sendo mais correto afirmar que a OMC envolve "um sistema de regras dedicadas à concorrência aberta, justa e não distorcida" do sistema mundial de comércio.

\section{http://revistasapereaude.org/index.php/edicoes/ano-5-volume-3-outubro-2016}

D.O.I: 10.20523/sapereaude-ano5-vol-3-pg-121-138 
A ausência de normas jurídicas comuns e a falta de comunicação impossibilitam o desenvolvimento da operação comercial. Dada a importância para a unificação do Direito Internacional Privado e uma tendência para que o idioma oficial seja o do destinatário (importador estrangeiro), quando não em inglês. Os aspectos culturais das exportações são de grande importância no processo decisório de compras e vendas internacionais, fazendo um paralelo com os principais Tratados, Acordos, e Blocos Econômicos que individualizam e protegem as suas próprias normas, inibindo a uniformização de normas internacionais.

A proximidade desta uniformização tão almejada por todos, pode ser encontrada no transporte marítimo, que emite em língua inglesa, o Conhecimento ou Certificado de Embarque, que comprova ter a mercadoria sido colocada a bordo do meio de transporte. Este documento é aceito pelos bancos como garantia de que a mercadoria foi embarcada para o exterior. $O$ documento corresponde ao título de propriedade da mercadoria e pode ser consignado ao importador. Além deste documento, serão analisados outros documentos que são descritos de forma uniforme no comércio internacional como a Fatura Comercial (Commercial Invoice), Romaneio (Packing List), Certificados de Origem, Contrato de Câmbio de Compra.

No intuito de se enfatizar a problemática da uniformização dos estatutos do comércio internacional, há um trabalho árduo de instituições internacionais contemporâneas como o Instituto de Roma (UNIDROIT) e a Comissão das Nações Unidas de Direito Internacional (UNCITRAL), das quais objetivam a uniformização e regulamentação do comércio internacional. 


\section{Lex mercatoria}

No comércio internacional surgem a cada dia novas modalidades de negociação, canais de distribuição e normas jurídicas que passam a conduzir essas atividades. Quando se encontra uma referência ao comércio internacional, é possível identificar, também, os elementos jurídicos, normas e costumes relacionados ao comércio internacional de mercadorias. Quando se analisa a problemática relativa ao comércio internacional é importante enfatizar os contratos internacionais, sobretudo, nos aspectos de sua normatividade e de sua elaboração.

O comércio é dividido entre o Mercado interno e externo, e respectivamente as concorrências nacionais e internacionais, tendo está última um maior número de competidores, obviamente. $O$ alicerce do comercio internacional é o transporte marítimo, que desde sua criação, vem aperfeiçoando de tempos em tempos a melhor forma de atender a demanda global de exportar e importar mercadorias. Está foi uma forma de comércio que melhor propiciou o acúmulo de mercadorias dentro de um container, onde neste baú de ferro fosse protegida até a chegada ao destino final, atravessando oceanos e cruzando as fronteiras imagináveis e inimagináveis deste planeta.

O direito comercial internacional moderno deve alguns de seus princípios fundamentais à Lex mercatoria desenvolvida na Idade Média, como a escolha de instituições e procedimentos arbitrais, de árbitros e da lei aplicável e o seu objetivo de refletir os costumes, uso e boa prática entre as partes. Muitos dos 
principios e regras da Lex mercatoria foram incorporados aos códigos e civis a partir do início do século XIX.

A Lex mercatoria foi um sitema jurídico desenvolvido pelos comerciantes da Europa medieval e que se aplicou aos comerciantes e marinheiros de todos os países do mundo até o século XVII. Não era imposta por uma autoridade central, mas evoluiu a partir do uso e do costume, à medida que os próprios mercadores criavam princípios e regras para regular suas transações. Este conjunto de regras era comum aos comerciantes europeus, com algumas diferenças locais.

A evolução da sociedade e seu desenvolvimento organizacional fazem com que haja o aperfeiçoamento das fontes dos princípios que regem a sociedade dos comerciantes. Ainda não havia uma separação clara entre a sociedade civil e os comerciantes internacionais no começo do século XIX, estes ainda não formavam uma sociedade autônoma. Os negociantes do mercado internacional celebravam contratos de venda conforme a técnica habitual, respeitando o Código Civil ou o Código Comercial (ou outras fontes legislativas nacionais) e aproveitando da liberdade contratual prevista pelo conjunto de direitos europeus para dispor das soluções legais.

Os textos legislativos, por emanarem de autoridade (competente) do governo, não eram questionados pelos tribunais, já que atendiam a ordem pública. Estes textos legislativos eram redigidos por comissões das quais participavam os maiores juristas da época, o que em combinação com o momento histórico próspero, reforçava a suposição de sua excelência. Até hoje é sentido o reflexo da tradição jurídica segundo a qual foram educados tais 
comerciantes e seus conselheiros, quando é observado que as condições gerais de venda estão impregnadas de direito inglês.

4. Facilitação do comércio internacional.

Os contratos de compra e venda eram frequentemente impostos pelo comércio britânico, o que permite supor uma "unificação do direito comercial sob a bandeira "inglesa" no século XIX". Com a primeira crise econômica capitalista (de superprodução) em 1917 e o começo da segunda metade do século XX, são rejeitadas muitas soluções antes admitidas. Há uma transformação radical e determinante do mundo comercial internacional e o papel do Estado teve que ser reanalisado, pois as relações econômicas ganhavam a cada dia proporção de grandeza maior que outrora, exigindo que se regulamentassem as relações entre diversos atores globais. São exemplos dessa dinamização a criação das casas de câmbio, o nascimento das instituições bancárias e das bolsas de valores, dentre outros. O comércio internacional buscava criar institutos que viabilizassem a total integração entre os mercados, o que pressupõe uma regulamentação supranacional.

A relação mundial entre países desenvolvidos e países com baixo índice de desenvolvimento também faz com que seja criada a necessidade de se normatizar as relações entre esses Estados, de forma a garantir o máximo de igualdade possível nas suas relações comerciais. No mundo globalizado é importante a relação pacífica entre Estados, bem como a solução pacífica de 
seus conflitos, defendida pelas organizações internacionais que surgem como organizações supranacionais legitimadas pelos próprios Estados.

Desta forma, o Estado talvez por temer perder competitividade, deixa de ser o único a editar normas e solucionar os conflitos advindos das relações comerciais internacionais, o que vai muito além dos conflitos oriundos das controvérsias existentes entre empresas de diversas nacionalidades, ou mesmo entre essas empresas e outros Estados. Tal fenômeno nos remete a Lex mercatória, onde destacamos três conceitos.

Segundo Irineu Strenger, Lex mercatoria pode ser entendida como: Um conjunto de procedimentos que possibilita adequadas soluções para as expectativas do comércio internacional, sem conexões necessárias com os sistemas nacionais e de forma juridicamente eficaz.

Outra definição que merece destaque é a de Antônio Carlos Rodrigues do Amaral: As regras costumeiras desenvolvidas em negócios internacionais aplicáveis em cada área determinada do comércio internacional, aprovadas e observadas com regularidade.

Já para Ana Paula Martins Amaral, Lex mercatoria seria: Um novo direito anacional, surgido no seio da comunidade dos comerciantes internacionais, formado por usos e costumes internacionais, jurisprudência arbitral e contratostipo.

Cada vez mais os Estados vêem com bons olhos o fenômeno de abrirem mão do seu domínio legal comercial internacional, abrindo espaço às boas práticas do mercado, como por exemplo, os INCOTERMS que são termos comumente seguidos pelos compradores e vendedores internacionais, onde é 
determinado entre as partes, o ponto inicial e final da responsabilidade de cada um no comércio internacional, desde a saída da mercadoria, até a sua chegada, no destino final.

$\mathrm{Na}$ época da Lex Mercatoria, ocorreu fenômeno muito parecido com o atual, onde a autoridade central que hoje é o Estado, que deixava aos poucos de interferir nas regras do comércio, que evoluia naturalmente a partir do uso e do costume, à medida que os próprios mercadores criavam princípios e regras para regular suas transações.

Hoje temos um princípio base do direito civil e do direito internacional que o "Pacta sunt servanda" que significa que "os pactos devem ser respeitados" ou "os acordos devem ser cumpridos". Com isto, e tendo em vista o sentimento de que a maior parte das transações internacionais ocorre com base nas boas práticas e a contentamento do comprador e vendedor, que tem como objetivo precioso voltarem a fazer negócio novamente, afirmamos com cautela que os estados deixam aos poucos de regulamentarem as transações internacionais, abrindo espaço para que organizações internacionais aprimorem e aperfeiçoem as regras de comércio internacionais, que por vezes demonstra ser mais dinâmica, e com maior segurança jurídica, do que a máquina estatal e os governos que nos países democráticos mudam de quatro em quatro anos, ou de em oito anos.

Outro ponto de destaque que faz com que nosso sentimento de que o Estado se distancia das relações comerciais internacionais, é o número crescente de litígios internacionais e nacionais que são resolvidos hoje por intermédio da arbitragem. Sem sobra de dúvidas, a arbitragem é a forma mais recomendável de solução de controvérsias surgidas no comércio internacional, e

http://revistasapereaude.org/index.php/edicoes/ano-5-volume-3-outubro-2016

D.O.I: 10.20523/sapereaude-ano5-vol-3-pg-121-138 
o Estado tendo consciência disto, não vai medir esforços para atrair e fomentar o comércio internacional, mesmo que para isso tenha que abrir mão do controle de fluxo do comércio internacional, quer seja por temer deixar de ser competitivo, que seja por se tornar a sexta principal economia global.

5. Solução de conflitos comerciais internacionais.

A solução de litígios por arbitragem ocorre quando as partes em um contrato estabelecem que as controvérsias sejam dirimidas por árbitros por elas indicados, com base na Lei ํㅜ 9.307/96, vem revolucionando as negociações comerciais.

Desde o final do século passado, muitos países revisaram suas legislações internas, para atrair fomentar o comércio internacional, tais como as leis francesa de 1981, inglesa de 1996, belga de 1998 e suíça de 1987. As leis dualistas têm por finalidade facilitar a solução de controvérsias internacionais, e com isto, propiciar ambiente neutro para as partes, menor interferência do Judiciário local, e dar tratamento diferenciado e condizente com as especificidades do comércio internacional. Neste sentido, as leis belga e suíça possibilitam até que as partes renunciem à possibilidade de recurso da sentença arbitral final.

É indubitável que a arbitragem é a forma mais usada e recomendada de solução de controvérsias surgidas no comércio internacional. Contudo, do ponto de vista operacional, algumas questões devem ser analisadas no momento em 
que os contratos internacionais são elaborados, pois geralmente a cláusula arbitral é esquecida, e somente é notada quando surge a controvérsia e se verifica que os custos podem ser mais altos do que se pressupunha.

O que ocorre na prática, é que geralmente o vendedor brasileiro, aceita sem questionar as cláusulas arbitrais sugeridas pelo comprador estrangeiro, que, na maioria das vezes, indica a sede da arbitragem no exterior e elege instituições arbitrais com taxas e custos altíssimos, que podem até inviabilizar o acesso à arbitragem. Contudo, como a cláusula arbitral tem efeito vinculante, é obrigatória e surgiu de consenso das partes, deverá ser cumprida e honrada sem discussão, posto que se assim não for violará o contrato, a lei e os tratados internacionais.

Os aspectos logístico, operacional e jurídico são de suma importância na formação dos contratos internacionais de compra e venda de mercadorias e dos contratos marítimos de transporte, fretamento e seguro. No custo da atividade empresarial, o Direito é um dos principais itens que interferem positiva ou negativamente no orçamento desta atividade, que devido às demandas jurídicas, pode o empreendedor prosperar ou não em suas atividades.

Toda empresa visa prevenir a demanda de litígios, a fim de minimizar os custos jurídicos, que incidirão de forma intrínseca no preço do produto final. Tal análise pode ser determinante para que um produto seja, ou não competitivo.

Imaginemos o importador que aguarda a chegada do produto eletrônico que será essencial para confecção de um maquinário de alto valor agregado. Ocorre que este importador da mesma forma, já firmou compromissos de entrega do seu produto a centenas de clientes, e que se por ventura este primeiro container 
não chegar no prazo determinado, acarretará na perda de diversos clientes para seu principal concorrente que também vende um produto de semelhante qualidade.

Tendo em vista o exemplo acima, torna-se óbvio o quão importante será está transação, e que quaisquer entreveros podem afetar de forma drástica a estabilidade destas duas empresas, sem ressalvas pode-se afirmar que poderão ocorrer situações em que uma empresa poderá até decretar sua falência devido a uma transação mal planejada juridicamente. Portanto, torna-se indispensável o conhecimento da sistemática das transações internacionais desde sua fase preliminar de negociação, pois todos os termos previamente negociáveis interferirão não só no custo da transação, mas em riscos e responsabilidades.

Dessa forma, a fase pré-contratual da negociação internacional assume extrema importância e engloba estratégias de minimização de custos, que trarão a tão desejada segurança jurídica. Nos contratos comerciais, é praxe a emissão de pro forma invoice ou fatura pro forma e a cata de intenção (letter of inttent). Já nesta fase que antecede o contrato internacional de compra e venda, devem as partes decidir a forma pela qual o contrato será regido, a forma depende da concordância entre as partes.

O contrato internacional de compra e venda pode ser formalizada através de um e-mail ou fax, conforme a confiança estabelecida pelas partes. A oralidade do contrato também é admitida, contudo, obviamente não é a forma mais indicada, segura e eficaz.

A fatura comercial emitida pelo exportador contém as informações detalhadas quanto à descrição e quantidade da mercadoria, dados do 
comprador/importador, tipo de transporte e porto de embarque ou destino, preço unitário e o valor total da fatura, data provável do embarque, formas e modalidades de pagamento, preço e Incoterm.

Nas negociações comerciais vem comumente sendo utilizadas as cartas de intenção, que contém motivos da negociação, direitos e obrigações, prazo, hipóteses de suspensão da negociação e imposição recíproca de sigilo e confidencialidade da transação.

Regra geral, nas negociações internacionais, o ponto de partida é representado pelas práticas Lex mercatoria e pelas manifestações do que se convencionou chamar de novo Lex mercatoria, tais como: usos e costumes do comércio internacional, contratos-tipo, condições gerais de venda, arbitragem comercial internacional e princípio da autonomia da vontade pelas partes em contratar.

A regulamentação das negociações comerciais é calcada em acordos internacionais e usos e costumes de diferentes portos, fazendo com que o direito marítimo se torne o protagonista nos conflitos de leis, sobretudo, aos que se referem aos contratos de transporte e fretamento marítimos.

No direito brasileiro não é reconhecido o princípio da autonomia de vontade das partes na escolha da lei aplicável aos contratos internacionais. Conforme a regra do direito internacional privado brasileiro referente à lei aplicável aos contratos, em geral, enaltece que as obrigações serão qualificadas e regidas pela lei do país no qual se constituírem, conforme reza o art. 9 da Lei de Introdução do Código Civil. 
Contudo, a jurisprudência vem assentando entendimento no sentido de não se admitir autonomia de vontade. E assim, na determinação de lei de regência, a regra vigorante é o art. 9 da lei de introdução ao Código Civil, que remete a aplicabilidade do país de celebração do contrato, independentemente de haver disposição contratual específica ou na omissão do contrato no referente à lei aplicável. A exceção à regra ocorre quando as partes optam pela arbitragem comercial com um mecanismo alternativo de solução de controvérsias que consagra a autonomia de vontades das partes em determinar a legislação aplicável ao procedimento arbitral.

Encontra-se em trâmite o Projeto de Lei n. 4095/95 que substituirá a LICC e adota o princípio da autonomia da vontade.

Em 2005, o STJ homologou o primeiro caso de sentença estrangeira de juízo arbitral envolvendo a empresa brasileira Têxtil União S.A. e a empresa Suíça L'Aiglon S.A.. Tendo sido este, o primeiro caso em que houve um pedido para homologação de sentença estrangeira realizada em juízo arbitral, a Corte Especial do Superior Tribunal de Justiça (STJ) deferiu a homologação, desconsiderando a alegação da Têxtil de não ter havido concordância na escolha da arbitragem para solução do processo por falta de assinatura. A homologação foi deferida mesmo com argumento de não assinatura de cláusula compromissória pela empresa têxtil. Segundo a Corte Especial, a Lei $n$. 9.307/96 e a Convenção de Nova York de 1958, ratificada pelo Brasil através do Decreto n. 4.311/2002, não exigem assinatura das partes como pressuposto da validade da cláusula compromissória. 
10. Referências Bibliográficas

1. BROWNLIEM, Ian. Principles of Public International Law. Editora: Oxford University Press, 2008.

2. CASSESSE, Antonio. International Law. Editora: Oxford University Press, 2005.

3. EDELMAN, Joel. The Tao of Negotiation. Editora: Harper Business, 1993.

4. ENGELBERG, Esther. Contratos Internacionais do Comércio. - $3^{\circ} e d$. São Paulo: Editora Atlas S.A, 2003.

5. GONÇALVES, Reinaldo. O Brasil e o Comércio Internacional. - 2ed. São Paulo: Editora Contexto, 2003.

6. HUSEK, Carlos Roberto. Curso de Direito Internacional Público. Editora: LTR, 2015.

http://revistasapereaude.org/index.php/edicoes/ano-5-volume-3-outubro-2016

D.O.I: 10.20523/sapereaude-ano5-vol-3-pg-121-138 
7. KISSINGUER, Henry. Diplomacy. Editora: Simon and Schuster Paper Backs, 1994.

8. MARTINS, Eliane M. Octavian. Curso de Direito Marítimo. - 1ed. Baruerí, São Paulo: Editora Manole, 2008.

9. SEGRE, German. Manual Prático de Comércio Exterior. - 2ed. São Paulo: Editora Atlas S.A, 2003.

http://revistasapereaude.org/index.php/edicoes/ano-5-volume-3-outubro-2016

D.O.I: 10.20523/sapereaude-ano5-vol-3-pg-121-138 